\title{
AC 2012-5516: PROMOTING STEM FACULTY MEMBERS' REFLECTION ON THEIR LEARNING PERCEPTIONS AND TEACHING PRACTICES
}

\section{Susan Shadle}

\section{Dr. Louis Nadelson, Boise State University}

Louis S. Nadelson is an Associate Professor in the College of Education at Boise State University. His research interests include STEM teaching and learning, faculty development, in-service and pre-service teacher professional development, program evaluation, and multidisciplinary research. He has published research ranging from faculty professional development to the impact of inquiry on STEM learning. Nadelson earned a B.S. degree in biological and physics science from Colorado State University, a B.A. with concentrations in computing, mathematics, and physics from the Evergreen State University, a secondary teaching certificate from University of Puget Sound, an M.Ed. in instructional technology leadership from Western Washington University, and a Ph.D. (research-based, not theoretical) in educational psychology from the University of Nevada, Las Vegas.

\section{Dr. Janet Callahan, Boise State University}

Janet Callahan is the Associate Dean for Academic Affairs at the College of Engineering at Boise State University and a professor in the Materials Science and Engineering Department. Callahan received her Ph.D. in materials science, her M.S. in metallurgy, and her B.S. in chemical engineering from the University of Connecticut. Her educational research interests include freshmen engineering programs, math success, K-12 STEM curriculum and accreditation, and retention and recruitment of STEM majors. 


\section{Promoting STEM Faculty Members' Reflection on their Teaching Practice}

As part of an institutional focus on STEM student success, a group of eight STEM faculty from across the STEM disciplines participated in a year-long faculty learning community (FLC). The facilitated experience was designed to support the professional development of faculty through exploration and adoption of research-based best practice in their pedagogy. A significant component of participant development involved promoting faculty reflection on both new ideas and on their teaching practice. We undertook to document and study the type of reflection undertaken by faculty in the group. Our analysis of participants' teaching logs shows that the experience expanded the reflective practice of participants and that from the participants' perspectives, their reflective work was linked to their exploration of new pedagogical approaches.

\section{Introduction}

Most university faculty members are more effective when they engage in high quality, best practices teaching, and yet, many have formally studied neither how people learn nor the pedagogies that best support student learning. ${ }^{1-3}$ While not unique to faculty in science, technology, engineering, and mathematics (STEM) disciplines, it is of particular importance that STEM faculty adopt evidence-based best practices in teaching to address challenges with student retention in STEM and the demand for a STEM prepared workforce. ${ }^{4}$

Traditionally, STEM faculty members have relied on the use of didactic instruction, a lecture and listen format for teaching and learning, as their primary pedagogical method. ${ }^{5-6}$ While it is common for STEM faculty members to become dissatisfied with the level of learning that their students achieve in lecture-based courses ${ }^{7}$; as Goldston and colleagues ${ }^{8}$ report, changing teaching practice is a complex process, particularly within the university and STEM culture.

In order to support faculty to adopt evidence-based best teaching practice, it is essential to provide professional development opportunities for faculty to consider the incorporation of these ideas into their teaching practice. With the support of a Science, Talent Expansion Program award from the National Science Foundation, we created, implemented, and studied a faculty learning community (FLC) program focused on STEM faculty professional development. An FLC is generally constructed as a group of about 8 trans-disciplinary faculty engaging in an active, collaborative, year-long program focused on enhancing teaching and learning. ${ }^{9}$ The STEM-focused FLC was constructed with the goals of a) increasing participants' knowledge about student learning and best pedagogical practices and b) facilitating the integration of those best practices into participants' teaching practice. Evidence exists that participation in an FLC can change faculty practice, ${ }^{10}$ but a great deal more study is needed to fully understand how, to what extent, and under what conditions FLCs support change, both short-term and sustained.

It is our hypothesis that reflective work is essential for faculty professional development; linking the knowledge faculty acquire through participation in an FLC with their teaching practice. We contend the development of STEM faculty members' sustained reflection about 
their teaching is ultimately linked to a shift in practice. Further, because FLCs build a supportive community of faculty, allow faculty to their share experiences with teaching, encourage exploration with instruction, and facilitate discussion of ideas about learning, reflective practice can be effectively fostered within an FLC. Because of the importance of reflective practice, we choose to specifically examine the reflective practice supported by participation in the STEMFLC. The following questions guided our study:

- In what kind of reflection do faculty participants in a STEM-FLC engage?

- What evidence is there that faculty reflections are connected to classroom teaching practice?

\section{Research Methods}

Study Participants and Structure of the Faculty Learning Community. Our study began with eight STEM faculty selected from a pool of applicants to be part of an FLC specifically structured to enhance STEM faculty knowledge of learning and teaching practices. One of the faculty members dropped out of the group after one semester due to workload issues. The remaining seven faculty members had appointments in chemistry, physics, mathematics, materials science, and mechanical engineering. They had either tenure line or full-time lecturer appointments and had been in these positions for zero to thirteen years. There were three females and four males. The group's facilitator was also a STEM faculty member with experience in faculty professional development work.

The FLC held a two-day retreat in August before the fall semester commenced and then met every other week for the duration of fall and spring semester. Although there was a facilitator for the group, participants rotated the responsibility for leading meetings. Each meeting focused on a specific topic relevant to STEM teaching and learning. Topics included: best-practice pedagogies, frameworks for student development, strategies for assessment, dealing with student misconceptions, a discussion of institutional student success data, and how STEM disciplines frame the context for teaching and learning. Each meeting lasted for 1 hour 45 minutes and used discussion, presentation, reflection, sharing, and readings to engage in deep exploration of the various STEM teaching and learning topics. In both the fall and spring semesters, the participants visited at least one other FLC participant's class. Finally, each participant completed either a course portfolio ${ }^{11}$ or a Scholarship of Teaching and Learning project focused on instructional practice and subsequent student learning that took place in his/her course.

Data Sources. The primary source of data for our study were derived from journals or logs kept by participants. Faculty participants were asked to keep a regular teaching log during the approximately 30 weeks of the academic year. While faculty were free to use whatever framework for their reflection that was most useful to them, the FLC facilitator provided the framework outlined in Table 1. The participants were instructed to reflect on one of their fall courses and one course in the spring. While the FLC faculty members were encouraged to make weekly entries into their logs, there was no requirement that each participant do so. Faculty were reminded about the logs at nearly every meeting, but the participants were not collected until the end of the year. One participant did not turn in a log at all, two participants made only fall entries ( 4 and 7 entries, respectively), one participant made 9 fall entries and 4 spring entries, and 
three participants made at least 29 entries over the course of the year, approximately evenly distributed over fall and spring. (One of the participants wrote considerably more entries because he/she maintained a log for more than one course). All but one of the logs used the suggested framework for all the logs. One faculty member switched to a more free-form journal format after the first three weeks of the academic year. A content analysis ${ }^{12}$ of the six teaching logs was conducted to expose trends and themes.

\section{Table 1. Suggested Framework for Teaching Logs}

\begin{tabular}{cl}
\hline \multicolumn{1}{c}{ Questions suggested for Teaching Log } \\
\hline 1 & $\begin{array}{l}\text { Learning Objectives for the week: } \\
2\end{array} \quad \begin{array}{l}\text { The following are examples of things that have } \\
\text { gone well with respect to my teaching and student } \\
\text { learning in my course(s): }\end{array}$ \\
3 & $\begin{array}{l}\text { The following are examples of things that I would } \\
\text { like to change with respect to my teaching and } \\
\text { student learning in my course(s): }\end{array}$ \\
& $\begin{array}{l}\text { The following are insights I have gained with } \\
\text { respect to my teaching and student learning in my } \\
\text { course(s): }\end{array}$ \\
\hline
\end{tabular}

In addition to the regular teaching logs, participants were invited to complete an evaluation of the FLC program at the end of the year. Five of the seven participants completed the survey, which included a range of questions about the experience, several of which are relevant to the development of reflective teaching practice.

\section{Results}

The analysis of the teaching logs revealed 15 teaching and learning themes, tabulated in Table 2. Although there were varying degrees of alignment between the participants' comments and the themes, they all reflected an important or critical aspect of teaching practice or insight into student learning.

All six logs included comments related to features of teaching that the instructor wanted to change (Theme A). This is not surprising, given that it was one of the suggested prompts for the log. Unrelated to a prompt, however, five of the logs mentioned implementing strategies which asked students to work in groups (Theme B) or described the use of some other new approach (Theme D). Other themes directly associated with faculty teaching practice included the introduction of real-world problems (Theme K), the use of student questions to drive instruction (Theme L), an attempt at the use of a strategy that didn't go as well as planned (Theme M), and the use of models (Theme N). In addition, five of the logs expressed some frustration over the tension of "coverage" of content in the course as the faculty member implemented new pedagogical strategies (Theme C).

The remaining themes reflected participants' paying close attention to evidence of student learning in the classroom. For example, four of the logs reflected engagement in 
observations that the best learning occurred for students when they struggled with problems (Theme E). Three of the logs noted higher-level questioning or questioning beyond the material from students (Theme $G$ ). The responses that fit into these student learning themes represent insight into pace, content, and student achievement, which are important aspects of being a reflective teacher.

Overall, our analysis revealed that the participants communicated a wide range of instructional concerns, successes, and insights into learning in their teaching logs. The logs also reflected the participants' experimentation with instruction, monitoring student learning, and thoughts about organization of content. While the frequency of entries varied across the sample of participants, the content of the logs revealed a great deal of consistency with respect to the content of the reflection on teaching and learning. Further, our log analysis suggests that the FLC effectively supported reflection both about classroom pedagogies and behaviors and about student learning in response to the learning environments fostered by the instructor.

Table 2. Teaching Log Themes

Theme

(Number of Faculty Responding)
Representative Response
Reflected on how they would change things for the next time or reflection on an aspect that they would like to change (6)

B Implemented the use of group work (5)

Expressed frustration in not being able to cover the $C \quad$ breadth of material that they have in the past, experienced being behind (5)

D Reflected positively about a new method that they tried (5)

E Found that the best learning occurs for students when they struggle with problems (4)

$\boldsymbol{F}$

Tried to predict student performance based on in class observations (4)

G Observed higher-level questioning or questioning beyond the material from students (3)

H Reflected on students' apparent satisfaction with class (3)
"A handful of students (3-4) dominate student participation - comments and questions. Today I was too heavy-handed in shutting down one of them."

"I had students work in groups and get to agreement and compare answers"

"Time management with the new method is still an issue. I am getting worried that I may not manage to cover everything and I do not know what to skip to get the more important parts."

"I think the applied problem is helping to keep the material more connected and relevant, and it makes a bigger difference than I would have thought."

"I still need to shift more of the problem solving over to the students. Watching is fine, but not much learning occurs. Learning occurs while the students are struggling with the problems. Maybe I can use the clickers to do some of this."

"The weakest student was the quietest, but some quiet students did really well."

"Students had all kinds of questions from things I thought they should know to questions that showed they were clearly thinking beyond the material."

"I notice that the environment of the classroom is one where, I believe, most students feel safe asking and answering questions, and testing out their theories." 


\section{Observed that when students develop their \\ I understanding of the content it is more powerful than when students receive their instruction through lecture (3)}

Noticed that an added benefit of student discussions and/or problem solving is that it helps identify misconceptions (3)

Found success in increasing student understanding $K \quad$ through introducing real world problems or events to drive instruction (3)

Used students questions to drive depth of instruction (2)

M

Experienced trying something new that didn't work out as expected. Expressed feeling like they had wasted valuable teaching time (2)

$N$

Used a physical model during instruction (2)

O Discovered that the way material is presented effects student learning (1)
"I think the applied problem is helping to keep the material more connected and relevant, and it makes a bigger difference than I would have thought."

"Students solved a problem, and throughout this exercise they asked questions and brought up their misconceptions."

"Students in both classes worked on the real world problems and got familiar with the format I want them to use."

"I managed to cover the same amount of material, but skipped some details, and the students came to those conclusions or asked about those and seemed to get it right away while I was beginning to explain those parts." "I asked them to solve a problem that was too much involved and they did not have the time for. Then, I solved it myself. I realized it took too much time and the class would have been better off receiving a handout of the solution. The time would have been spent better on something else."

"The demonstrations of reflection and refraction have gone well with the magnetic board mount optics."

"It is all about presentation! Part of how it was presented was good, but it's not good enough. A little more time (taken from answering questions on previous HW) to do an extra application and to go a little slower may help."

In addition to the teaching log analysis, several questions on the end-of-program evaluation provided insight into the impact of the program on faculty reflective practice. For example, all the respondents indicated that the program helped them to "try new teaching approaches" and "better understand a variety of ways to be an effective teacher" to a "moderate" or "significant extent". Further, all the respondents indicated the FLC helped them "reflect on their own personal growth as a teacher" to a "significant extent." This response, in particular, suggests that the reflective practice supported by the program, was particularly important. Several open-ended questions invited participants to identify what was valuable to them about the program. Nearly all respondents identified the ways in which the program helped them to consider new ideas, reflect on them in a sustained way, and support them to implement new approaches in their teaching. The following are representative responses.

The sustained, in-depth discussion that took part over a whole academic year [was the best part of being in the FLC]. Without this (e.g., if it had been a oneday or weekend workshop) I would have listened, then forgot. This gave me a chance to think about things and ask questions in the next meeting; to try something and report on it in the next meeting.

The program helped me to engage in reflective teaching and created some collegial relationships which will be useful.

[The FLC] changes your thinking about how and why you teach, and what your ultimate goal is. If your goal is that your students gain as much understanding as possible, you can't sit back and do the same old thing. 
These responses suggest that faculty participants were aware of the value of the new information gained in the program and the opportunity to reflect on it. Further, the comments suggest that faculty perceive a direct connection between their reflective practice and the pedagogical choices they make in their teaching.

\section{Discussion}

Our data show that faculty participants in a STEM-FLC engage in reflective work around their own classroom pedagogy and about student learning in their classroom environment. While it is possible that faculty outside the FLC were also engaging in similar reflective work, this does not seem likely. First, not all participants sustained written reflective practice throughout the entire year. Reflective work takes time and energy and, unless it is prompted and supported, even well-intentioned faculty can let it slide. Second, there is also evidence that even those participants who engaged in completing teaching log entries did not immediately see the value of the reflective work. A second semester entry from one participant reflects this perspective.

I have been avoiding writing in this log and I have figured out why. I did not understand the purpose of a reflective log. During busy times... a meaningless activity gets dropped fast! I decided this week that the purpose of the log is to help me make progress on my teaching goals by reflective learning. All I need to do is to reflect on my teaching goals. Therefore, I should list my teaching goals to keep them in front of my eyes!

It is important to recognize that this individual had already completed over $15 \mathrm{log}$ entries during the fall semester and that the FLC had discussed the purpose of the logs on several occasions. This suggests that it takes time and support to internalize the value of reflective practice.

This FLC-based approach was effective in supporting reflection for a group of full-time STEM faculty. While little work has been done to explore FLCs as a strategy to support reflection among other groups, one study shows that virtual FLCs effectively connect online faculty to their institution. ${ }^{13}$ There is reason to believe, then, that FLCs may be useful for supporting professional development for other STEM faculty.

While there is evidence in our data that faculty perceive that the FLC experience supported them to make changes in their teaching practice, and that faculty reflection seems directly linked to these changes in practice, it is unclear from this work how significant those changes were or whether those changes would be sustained over time. Thus, while the reflective practice observed here seems to be an essential step in the professional development of these faculty, additional study is needed to look carefully at our contention that reflection supported by the FLC will lead to changed professional teaching practice. Further, additional work needs to be done to establish that FLC-supported reflection can be effective for other groups of faculty (e.g., part-time faculty, or faculty participating in a community at a distance).

\section{Acknowledgments}


This material is based upon work supported by the National Science Foundation under Grant No. 0856815. Any opinions, findings, and conclusions or recommendations expressed in this material are those of the author(s) and do not necessarily reflect the views of the National Science Foundation. 


\section{References}

1. Centra, J. (1976). Faculty development practices in US college and universities (New Jersey, Educational Testing Service). Retrieved from: http://eric.ed.gov/PDFS/ED141382.pdf

2. Flick, L., Sadri, P., Morrell, P.D., Wainwright, C., \&Schepige, A. (2009). A cross discipline study of reformed teaching by University science and mathematics faculty. School Science and Mathematics Journal, 109, 4, 197-211.

3. Momsen, J., Long, T., Wyse, S., \& Ebert-May, D. (2010) Just the facts? Introductory undergraduate biology courses focus on low level cognitive skills. CBE Life Science Education, 9(4), 435-440.

4. Carnevale, A. P., Smith, N. \& Melton, M. (2011). STEM. Georgetown University Center on Education and the Workforce. Retrieved from: http://cew.georgetown.edu/STEM/

5. Lindblom-Ylanne, S., Trigwell, K., Nevgi, A., \&Ashwin, P. (2006). How approaches to teaching are affected by discipline and teaching context. Studies in Higher Education, 31, 285-298.

6. Lueddeke, G. (2003).Professionalising teaching practice in higher education: a study of disciplinary variation and 'teaching-scholarship.' Studies in Higher Education, 28, 213 228.

7. Handelsman, J., Egert-May, D., Beichner, R., Bruns, P., Change, A., DeHaan, R., et al. (2004). Scientific teaching. Science, 304, 521-522.

8. Goldston, D., \& J. Bland (2002). Trailing Halley's Comet: Transforming science, mathematics, and technology education through interdisciplinary collaborations in higher education. School Science and Mathematics. 102(6), 241-4.

9. Cox, M.D. (2004).Introduction to Faculty Learning Communities. New Directions in Teaching and Learning, 97 (5-23).

10. Polich, Susan (2008) Assessment of a Faculty Learning Community Program: Do Faculty Members Really Change?To Improve the Academy, 26, 106-118.

11. Cerbin, W. (1994). The course portfolio as a tool for continuous improvement of teaching and learning. Journal on Excellence in College Teaching, 5(1), 95-105.

12. Miles, M. B. \& Huberman, A. M. (1994). Qualitative data analysis (2nd ed.). Thousand Oaks, CA: Sage.

13. Velez, Angela M. (2009). The Ties that Bind: How Faculty Learning Communities Connect Online Adjuncts to Their Virtual Institutions. Online Journal of Distance Learning Administration, 12(2), 5 pp. 